\title{
Influence of Pleural Drain Insertion in Lung Function of Patients Undergoing Coronary Artery Bypass Grafting
}

\author{
Irinea Beatriz Carvalho Ozelami Vieira ${ }^{1}$, Fabiano F. Vieira ${ }^{2}$, João Abrão ${ }^{3}$, Ada Clarice Gastaldi ${ }^{3}$
}

Summary: Ozelami Vieira IBC, Vieira FF, Abrão J, Gastaldi AC - Influence of Pleural Drain Insertion in Lung Function of Patients Undergoing Coronary Artery Bypass Grafting.

Background and objectives: Longitudinal, prospective, randomized, blinded Trial to assess the influence of pleural drain (non-toxic PVC) site of insertion on lung function and postoperative pain of patients undergoing coronary artery bypass grafting in the first three days post-surgery and immediately after chest tube removal.

Method: Thirty six patients scheduled for elective myocardial revascularization with cardiopulmonary bypass (CPB) were randomly allocated into two groups: SX group (subxiphoid) and IC group (intercostal drain). Spirometry, arterial blood gases, and pain tests were recorded.

Results: Thirty one patients were selected, 16 in SX group and 15 in IC group. Postoperative (PO) spirometric values were higher in SX than in IC group $(\mathrm{p}<0.05)$, showing less influence of pleural drain location on breathing. $\mathrm{PaO}_{2}$ on the second $\mathrm{PO}$ increased significantly in $\mathrm{SX}$ group compared with IC group $(p<0.0188)$. The intensity of pain before and after spirometry was lower in SX group than in IC group $(p<0.005)$. Spirometric values were significantly increased in both groups after chest tube removal.

Conclusion: Drain with insertion in the subxiphoid region causes less change in lung function and discomfort, allowing better recovery of respiratory parameters.

Keywords: Chest tubes; Coronary artery bypass grafting; Pneumothorax; Pain, Postoperative; Pain Measurement; Spirometry.

\section{INTRODUCTION}

Change in lung function increases morbidity and mortality in coronary artery bypass grafting ${ }^{1}$. Several factors contribute to this, such as median sternotomy, cardiopulmonary bypass ${ }^{2,3}$, pleurectomy, and postoperative pain 4 .

The use of left mammary artery, although a worldwide accepted technique, involves pleurotomy ${ }^{5}$ that together with sternotomy promote major changes in lung mechanics, which predisposes to decreased vital capacity and total lung capacity ${ }^{6}$.

The fact that pleurotomy is always associated with pleural drainage causes more discomfort and pain to the patient, which further worsens lung function ${ }^{6-9}$. Guizilini et al. studied the effect of pleural drain site of insertion on postoperative lung function in coronary artery bypass grafting and found that, regardless of drain positioning, pain and loss of lung

Received from Hospital de Clínicas da Faculdade de Medicina da Universidade do Triângulo Mineiro, Uberaba, MG, Brazil.

1. Physiotherapist, Universidade Federal do Triângulo Mineiro, Uberaba, MG

2. Cardiac Surgeon, Department of Surgery, Universidade Federal do Triângulo Mineiro, Uberaba, $M G$

3. PhD, Professor, Department of Biomechanics, Medicine and Locomotive Apparatus Rehabilitation, Faculdade de Medicina de Ribeirão Preto, Universidade de São Paulo, SP

Submitted on November 2, 2011.

Approved on March 8, 2012.

Correspondence to:

João Abrão, $M D$

Av. Bandeirantes, 3900

14049900 - Ribeirão Preto, SP, Brazil.

E-mail: joaoabrao@fmrp.usp.br function occurred, although the effects were less noticeable when the drain was placed in the subxiphoid region ${ }^{10}$. Chest tubes are made from various raw materials and all seem to work satisfactorily regarding blood drainage from the pleural space and the pain of withdrawal procedure ${ }^{11}$. Chest tube itself can interfere with deep inspiration by its intimate contact with the visceral pleura. Misplacement of a thick rigid tube may result in serious complications, such as arrhythmia due to heart irritation; injury of the intercostal nerves, parietal pleura or lung parenchyma ${ }^{12}$; erosion of intrathoracic major vessels; and cardiac tamponade ${ }^{13}$.

\section{OBJECTIVE}

The aim of this study is to evaluate the influence of the insertion site of a PVC non-toxic chest tube on lung function by spirometry in the first days after surgery. As a control, the same parameters were evaluated without the chest tube on the third day. As a secondary objective, we assessed the discomfort caused by chest tube insertion using pain registration at rest and after spirometry.

\section{METHOD}

A prospective randomized study of patients with coronary artery disease who underwent elective coronary artery bypass surgery was conducted at the Hospital das Clínicas, Univer- 
sidade Federal do Triangulo Mineiro (UFTM); such patients were admitted to the Intensive Care Unit from January 2010 to July 2011. After approval by the Ethics Research Committee of UFTM and obtained informed consent, 36 patients were included in the study. During surgery, the service assistant held the draw of the envelope containing the chest tube site of placement, and the patients were then allocated into two groups (intercostal [IC] or the subxiphoid [SX]). Inclusion criteria were patients with coronary artery disease proven by coronary angiography, who underwent elective coronary artery bypass grafting using the left internal thoracic artery (mammary), left pleurotomy with cardiopulmonary bypass (anoxia time $<60 \mathrm{~min}$ ), ejection fraction greater than $50 \%$, and normal spirometry. Patients with previous lung disease, those who could not perform pulmonary function tests, remained intubated beyond the first postoperative day (PO-1), and required surgical intervention were excluded. Five patients were excluded: two for decreased level of consciousness (SX) and two for prolonged intubation and one by death (IC).

Spirometric measurements, forced vital capacity (FVC), and forced expiratory volume in one second $\left(\mathrm{FEV}_{1}\right)$ were performed preoperatively and in the intensive care by a physiotherapist who was blinded to the method and recorded in a detailed evaluation form, which contained diagnostic, nutritional status, risk factors for coronary heart disease (hypertension, diabetes mellitus, dyslipidemia, and smoking habit), and associated diseases.

Computed spirometry was performed with a portable spirometer Multispiro (Creative Biomedics, San Clemente, CA, EUA) certified by CE and ISO standard 9001/EN46001, with high accuracy and reproducibility. For greater accuracy of measurements, each test was repeated three times, and the best result was recorded. Measurements were always made at the bedside, after training, with the patient at the sitting position (erect trunk) and using a nose clip. The subjects were asked to breathe slowly and deeply as possible and, after a brief inspiratory pause, to expire as fast as possible. The technique and selection of the values from lung mechanics results followed the guidelines for pulmonary function tests of the Sociedade Brasileira de Pneumologia e Tisiologia (Brazilian Society of Pulmonology and Phthisiology) ${ }^{14}$.

Arterial blood gas analysis, according to service routine, was made before surgery with the patient breathing room air and after surgery, on first and second days, with patients still on nebulizer mask with continuous flow at 5 L.min ${ }^{-1}$.

Surgery was performed through median sternotomy with cardiopulmonary bypass (CPB). After the operation, before chest closure and under direct vision, a chest tube of nontoxic PVC, number 34F, was used for thoracic drainage. In IC group, the tube was inserted in the sixth intercostal space in the midaxillary line. In SX group, the tube was placed in the subxiphoid region. All patients left the surgery with mediastinal drainage (chest tube 36F), via subxiphoid. The protocol for general anesthesia was balanced general anesthesia (isoflurane and fentanyl). All patients were ventilated with a tidal volume of $8 \mathrm{~mL} . \mathrm{kg}^{-1}$ without positive end-expiratory pressure (PEEP) and $\mathrm{FIO}_{2}$ of $100 \%$.
After surgery, patients were taken to the postoperative unit of cardiac surgery and maintained on mechanical ventilation, initially ventilated with $100 \% \mathrm{FiO}_{2}$, tidal volume of $8 \mathrm{~mL} \cdot \mathrm{kg}^{-1}$, PEEP of $5 \mathrm{~cm} \mathrm{H}_{2} \mathrm{O}$. Extubation was performed according to the intensive care unit criteria.

Radiological evaluation was performed daily to assess the diaphragm position, fluid retention, and atelectasis. Pleural tubes were removed after spirometry on the second postoperative day. Spirometric values were recorded in the first, second and third days after surgery.

The subjective sensation of pain was measured by Verbal Analog Scale (VAS) with pain scores 0 to $10(0=$ no pain, $10=$ worst possible pain). Measurements were performed at rest and after spirometry in the first, second, and third postoperative day. The same physiotherapist was responsible for the assessments.

Body mass index (BMI) calculated by the ratio weight. height $^{-2}$ was used to assess nutritional status, as recommend-

Table I - Comparison between Groups, Sociodemographic Variables, Risk Factors, Pre-surgical Pulmonary Function, Blood Gases

\begin{tabular}{|c|c|c|c|}
\hline \multirow[b]{2}{*}{ Variables } & \multicolumn{3}{|l|}{ Group } \\
\hline & $\begin{array}{l}\text { Subxiphoid } \\
(n=16)\end{array}$ & $\begin{array}{l}\text { Intercostal } \\
(n=15)\end{array}$ & p \\
\hline Age (years) ${ }^{*}$ & $56.43 \pm 9.04$ & $59.20 \pm 8.40$ & $0.1932 \dagger$ \\
\hline \multicolumn{4}{|l|}{$\operatorname{Sex}(n, \%)$} \\
\hline Male & $12(75.0)$ & $8(53.33)$ & \multirow[t]{2}{*}{$0.2080 \ddagger$} \\
\hline Female & $4(25.0)$ & $7(46.67)$ & \\
\hline Weight $(\mathrm{kg})^{*}$ & $76.25 \pm 9.63$ & $77.06 \pm 11.96$ & $0.4176 \dagger$ \\
\hline Height $(\mathrm{cm})^{\star}$ & $166.62 \pm 6.60$ & $163.80 \pm 8.43$ & $0.8470 \dagger$ \\
\hline BMI $\left(\mathrm{kg} \cdot \mathrm{m}^{-2}\right)^{*}$ & $27.50 \pm 3.15$ & $28.69 \pm 3.23$ & $0.3737 ¥$ \\
\hline \multicolumn{4}{|l|}{ Risk factors $(\mathrm{n}, \%)$} \\
\hline Hypertension & $12(75.0)$ & $15(100.0)$ & $0.0380 \ddagger$ \\
\hline Diabetes & $5(31.25)$ & $8(53.33)$ & $0.2130 \ddagger$ \\
\hline Dyslipidemia & $7(43.75)$ & $9(60.0)$ & $0.3660 \ddagger$ \\
\hline \multicolumn{4}{|l|}{ Smoking $(n, \%)$} \\
\hline Non-smoker & $6(37.50)$ & $7(46.67)$ & \multirow[t]{3}{*}{$0.8280 \ddagger$} \\
\hline Smoker & $7(43.75)$ & $5(33.33)$ & \\
\hline Ex-smoker & $3(18.75)$ & $3(20.00)$ & \\
\hline \multicolumn{4}{|l|}{ Lung function } \\
\hline \multicolumn{4}{|l|}{ Pre-surgical } \\
\hline $\mathrm{FVC}(\mathrm{L})^{*}$ & $3.25 \pm 0.65$ & $3.12 \pm 0.76$ & $0.3058 \dagger$ \\
\hline$\%$ expect FVC * & $3.75 \pm 0.63$ & $3.55 \pm 0.79$ & $0.2272 \dagger$ \\
\hline$\% \mathrm{FVC}^{*}$ & $86.58 \pm 7.51$ & $88.23 \pm 11.88$ & $0.9685 ¥$ \\
\hline FEV1 $(L)^{*}$ & $2.60 \pm 0.49$ & $2.54 \pm 0.61$ & $0.6101 \dagger$ \\
\hline$\%$ expect FEV1* & $2.98 \pm 0.54$ & $2.80 \pm 0.65$ & $0.2082 \dagger$ \\
\hline FEV1 \%* & $87.50 \pm 7.45$ & $91.19 \pm 11.91$ & $0.4064 ¥$ \\
\hline Blood gases * & $82.93 \pm 9.89$ & $81.93 \pm 10.65$ & $0.3937 \dagger$ \\
\hline CPB (min) & $69.75 \pm 14.79$ & $63.80 \pm 12.84$ & $0.1215 \dagger$ \\
\hline Anoxia (min) & $41.37 \pm 8.75$ & $40.33 \pm 9.98$ & $0.3796+$ \\
\hline
\end{tabular}

*: Mean values \pm standard deviation; $\dagger$ : Student's t test; $\ddagger$ : Chi-Square test; $¥:$ Wilcoxon-Mann-Whitney test; BMI: Body Mass Index: FVC: forced vital capacity; \% expect FVC: percentage of expected forced vital capacity; FEV1: Forced Expiratory Volume in the first second; CPB: cardiopulmonary bypass. 
ed by the $\mathrm{WHO}{ }^{15}$. BMI > $30 \mathrm{~kg} \cdot \mathrm{m}^{-2}$ was considered obesity; patients who have smoked at least one cigarette per day were considered current smokers; patients who had stopped smoking for at least one year were considered ex-smoker; and patients who had never used tobacco-derived substances were considered non-smokers ${ }^{16}$.

The sample size calculation was based on the variable FVC and a difference of at least $400 \mathrm{~mL}$ between groups or in relation to preoperative period was considered clinically relevant. Beta risk of $20 \%$, alpha risk of $5 \%(p<0.05)$, and a test power of $80 \%$ were considered to detect this difference and the sample calculation.

Data normality was assessed using the Shapiro-Wilk test. For intergroup comparison, Student the $t$ test was used for parametric continuous variables and Wilcoxon-Mann-Whitney test for nonparametric continuous variables. Dichotomous variables were analyzed using chi-square test. For intergroup comparison, the paired Student $t$ test was used for normally distributed variables and Wilcoxon matched pairs test for the other. The significance level was $5 \%$. Analyzes were performed using Stata 11.2 software for Windows.

\section{RESULTS}

We evaluated 31 patients in the study, 16 patients in SX group and 15 in IC group. The sociodemographic variables, risk factors, measures of pulmonary function, blood gases, and duration of cardiopulmonary bypass (CPB) showed no significant variation between groups, except for hypertension that was more prevalent in the IC group (Table I). Spirometry records were made postoperatively for three days and compared with

Table II - Inter and intragroup Comparison of the Studied Variables

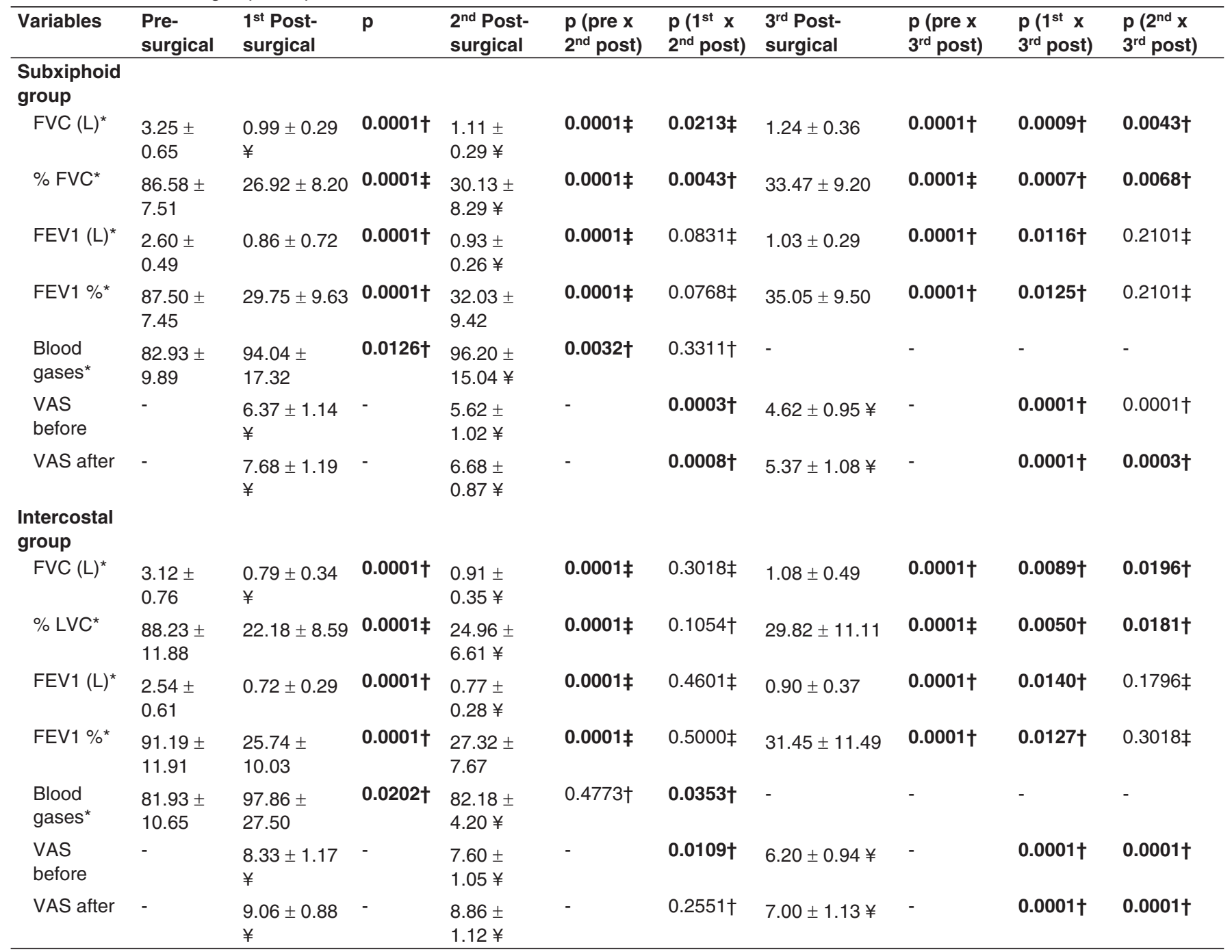

*: Mean values \pm standard deviation; $\uparrow$ : Student’s pared t-test; $\ddagger$ : Wilcoxon pared test; $¥: p<0.05$ between subxiphoid and intercostal groups; BMI: Body Mass Índex: FVC: forced vital capacity; FEV1: Forced Expiratory Volume in the first second; VAS; Visual Analog Scale of pain. 
preoperative values, whenever appropriate and a significant change in forced vital capacity and forced expiratory volume in the first second was found in both groups. In the analysis of postoperative variables (mean and standard deviation) in

Table III - Analysis of Postoperative Values in Relation to Preoperative Periods of the Studied Groups

\begin{tabular}{|c|c|c|c|}
\hline \multirow[b]{2}{*}{ Variables } & \multicolumn{3}{|l|}{ Groups $†$} \\
\hline & $\begin{array}{l}\text { Subxiphoid } \\
(n=16)\end{array}$ & $\begin{array}{l}\text { Intercostal } \\
(n=15)\end{array}$ & $\mathbf{p}$ \\
\hline \multicolumn{4}{|l|}{$1^{\text {st }}$ Post-surgical } \\
\hline $\mathrm{FVC}(\mathrm{L})^{*}$ & $2.26 \pm 0.58$ & $2.32 \pm 0.70$ & 0.3879 \\
\hline$\%$ FVC $^{\star}$ & $55.51 \pm 11.26$ & $62.88 \pm 16.70$ & 0.0789 \\
\hline FEV1 $(L)^{*}$ & $1.73 \pm 0.44$ & $1.82 \pm 0.53$ & 0.3117 \\
\hline$\%$ FEV1* & $53.61 \pm 11.88$ & $63.09 \pm 14.69$ & 0.0285 \\
\hline Blood gases* & $-11.10 \pm 17.86$ & $-15.92 \pm 27.32$ & 0.2815 \\
\hline \multicolumn{4}{|l|}{$2^{\text {st }}$ Post-surgical } \\
\hline $\mathrm{FVC}(\mathrm{L})^{*}$ & $2.14 \pm 0.58$ & $2.21 \pm 0.62$ & 0.3686 \\
\hline FVC \%* & $51.83 \pm 11.01$ & $59.58 \pm 16.39$ & 0.0654 \\
\hline FEV1 (L)* & $1.66 \pm 0.42$ & $1.76 \pm 0.53$ & 0.2699 \\
\hline FEV1 \%* & $51.10 \pm 10.14$ & $60.95 \pm 16.16$ & 0.0249 \\
\hline Blood gases* & $-13.26 \pm 16.72$ & $-0.24 \pm 16.50$ & 0.0188 \\
\hline \multicolumn{4}{|l|}{$3^{\text {st }}$ Post-surgical } \\
\hline $\mathrm{FVC}(\mathrm{L})^{*}$ & $2.00 \pm 0.55$ & $2.04 \pm 0.56$ & 0.4371 \\
\hline FVC \%* & $47.93 \pm 11.93$ & $54.68 \pm 14.53$ & 0.0835 \\
\hline FEV1 (L) & $1.56 \pm 0.41$ & $1.64 \pm 0.48$ & 0.3239 \\
\hline FEV1 \%* & $47.57 \pm 11.13$ & $56.99 \pm 13.92$ & 0.0228 \\
\hline
\end{tabular}

*: Mean values \pm standard deviation variation; $\dagger$ : comparisons by Student's $t$ test; FVC: forced vital capacity; FEV1: Forced Expiratory Volume in the first second. order to compare the two groups, SX group showed lower loss of FVC and FEV $\mathrm{F}_{1}$ than group IC at all times (Table II).

Post-operative lung function, when compared with baseline values, were analyzed and showed that the loss in $\mathrm{FEV}_{1}$ and FVC was always lower in SX group than in IC group (Table III).

Postoperative pain evaluation was made before and after expiratory effort in order to assess the influence of chest tube position. There was a significantly reduced intensity at all times in SX group compared to IC group (Figure 1).

$\mathrm{PaO}_{2}$ analysis in both groups, when compared with preoperative values, using the mean change in blood gas, showed that in the first postoperative day the mean was similar between groups. However, in the second PO, the SX group had a $\mathrm{PaO}_{2}$ significantly greater than the IC group (Figure 2).

\section{DISCUSSION}

The insertion site of the non-toxic PVC chest tube had influence on lung function, which was shown by the decrease in FVC and FEV1 values recorded postoperatively. SX group showed better spirometric measurements and less pain compared to IC group. When chest tubes were removed, there was further improvement in measured values due to decreased pain, with SX group values closer to preoperative values.

The change in pulmonary function after coronary artery bypass grafting with CPB has a multifactorial dependency. In addition to sternotomy, pleurotomy ${ }^{17}$ and pain in the postoperative period ${ }^{18}$ contribute to decline in lung function. Other factors are also implicated in the reduction of postoperative ventilation, such as surgical manipulation, use of cardiopulmonary bypass (CPB), anesthesia, mechanical ventilation,

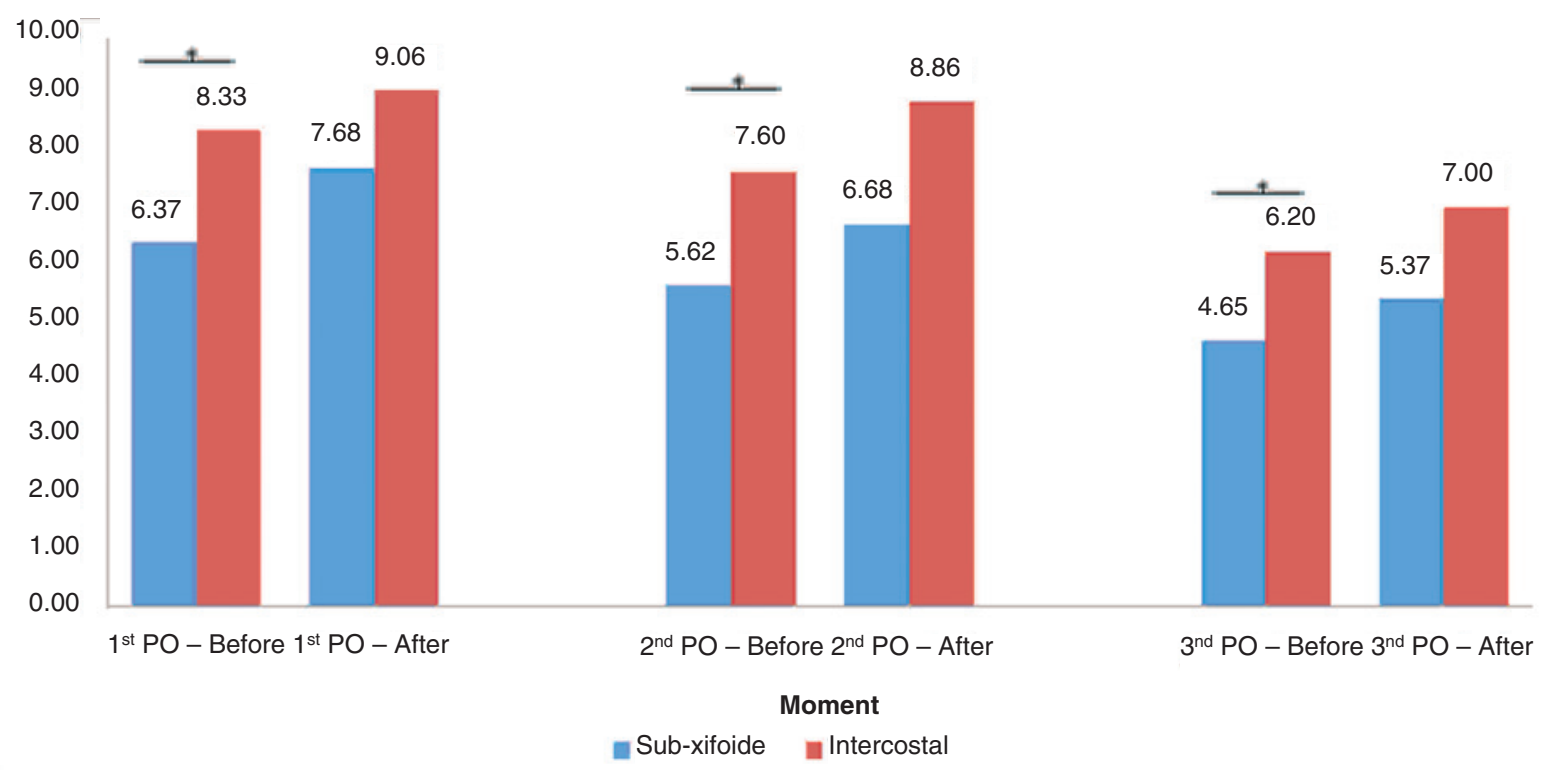

Figure 1 Assessment of Pain before and after Expiratory Effort within Postoperative three Days.

${ }^{*} p<0.05$; PO: Postoperative. 


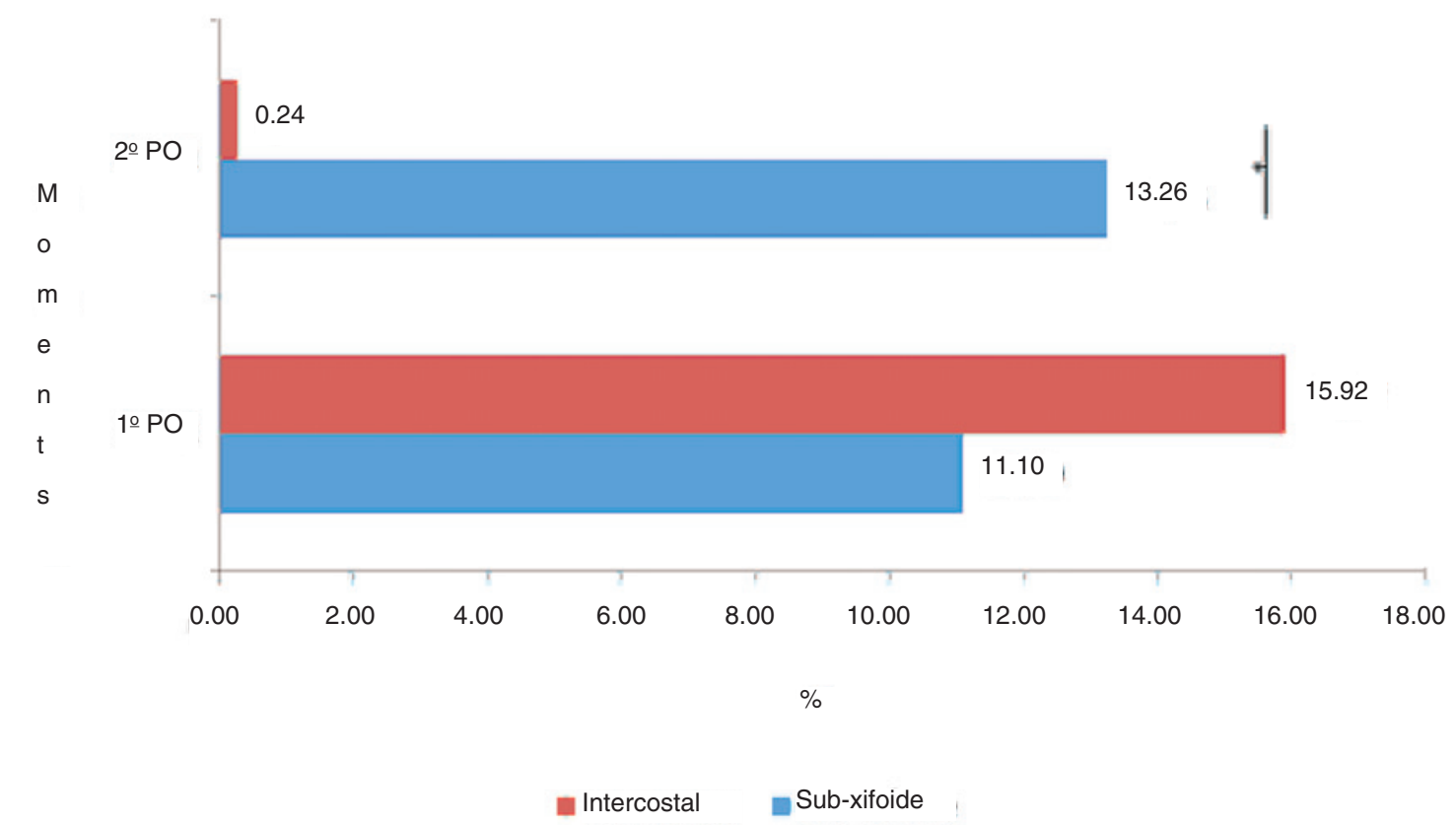

Figure 2 Distribution of Mean Percent Change of Gasometry according to Group and Postoperative Measurments. ${ }^{*} \mathrm{p}<0.05$; PO: Postoperative.

and use of drains ${ }^{19}$. Chest wall edema and change in surfactants are important factors in reducing lung volume and capacity 20,21 .

The surgical technique used in coronary by-pass also affects the decrease in FVC, as demonstrated by some authors comparing the use of saphenous vein graft to the internal mammary artery ${ }^{22}$. It is known that the removal of internal thoracic artery can reduce blood supply to the phrenic nerve, resulting in additional pulmonary dysfunction in the postoperative period ${ }^{23}$. The incidence of pulmonary complications after cardiac surgery is significant, and may worsen during the evolutionary picture of the patient, being the leading cause of morbidity and mortality ${ }^{24}$.

A better understanding of the factors responsible for lung damage is needed to minimize the pulmonary dysfunction associated with cardiac surgery and its repercussions.

Chest tube causes discomfort to the patient, facilitating the deterioration of respiratory mechanics ${ }^{4,25}$. Cohen et al. ${ }^{26}$ found that postoperative pain with the use on internal mammary artery is significantly higher than with saphenous vein, and may itself lead to a reduction in respiratory function. This is explained by the greater restriction on effective coughing, deep breathing, and changes in position ${ }^{26}$. Authors state that the reduction in lung function when using the internal mammary artery for revascularization would be due to pleurotomy, greater thoracic manipulation, and pain ${ }^{22,27}$. All these factors contribute to a higher incidence of atelectasis, making patients more vulnerable to hypoxic pulmonary complications, mainly pneumonia ${ }^{4}$.

Reduced lung function in the postoperative period is influenced by different factors, and pain interference in the respiratory movements is evident. In our study, in addition to evaluating the influence of the chest tube position, we made a counter-proof by measuring the lung volumes and capacities after removal of chest tubes.

Chest tubes placed in the subxiphoid region caused less pain than those in the intercostal space, results in agreement with literature ${ }^{4,28}$. Some authors attributed chest pain to the technique of tube insertion (major or minor tissue injury) and friction in the intrathoracic structures ${ }^{2}$. Corroborating these arguments, we noted lower values for respiratory function parameters in both groups in the first postoperative day, with a gradual improvement until the third postoperative day, culminating with chest tube removal. Although there was recovery in both groups, the values of SX group were very close to the preoperative period.

Guizilini et al. ${ }^{10}$ conducted a similar study, but in patients without $\mathrm{CPB}$, and found results similar to ours, although they did not study the immediate effect of chest tube removal ${ }^{10}$.

Decreased lung volume and capacity persists in the fifth postoperative day, but due to other factors, such as CPB and surgical incision ${ }^{29}$.

Clinically, the decrease in FVC leads to reduced peak expiratory flow, reducing the ability to cough, which hinders the movement of secretions predisposing to atelectasis and pneumonia ${ }^{30}$.

Different from Hagl et al. ${ }^{4}$ who found no difference in $\mathrm{PaO}_{2}$ between groups, we found a significant decrease in $\mathrm{PaO}_{2}$ in the second PO in IC group. This may be explained by processes other than individual supplements of oxygen. In our work this supplementation was set at $5 \mathrm{~L}$. $\mathrm{min}^{-1}$ and not on demand. Something that can also influence the respiratory parameters is the presence of residual fluid in the chest, which could be assessed by ultrasound or by radiography. Studies 
in this direction were made and showed that the efficiency of chest drainage depended on chest tube correct positioning ${ }^{31-33}$. In our study, the tube was placed under direct vision before chest closure, ensuring the proper positioning. Analyzing the painful effects, Guizilini states that intercostal chest tube placement increases postoperative pain, with restriction of deep breathing, coughing, and changing patient's position on the bed ${ }^{10}$, findings that are consistent with our results.

Postoperative atelectasis is associated with decreased oxygenation and ventilation in dependent areas, increased pulmonary vascular resistance, as well as development of lung injury ${ }^{34}$. Pain limits the rib cage voluntary expansion and, consequently, increases the non-ventilated areas. The ability to cough is reduced, which may induce secretion retention followed by atelectasis progression with consequent hypoxemia. Ultimately, pain causes acid-base imbalances, which may contribute to increased morbidity and mortality 18,35 .

According to Jakob et al. ${ }^{36}$, the postoperative patient evolves into a shallow inspiration due to constant irritation of the intercostal nerves and periosteum ${ }^{36}$.
Noteworthy, there was improvement in FVC in the third postoperative day (without chest tube) compared with the second postoperative day (with chest tube) in both groups, which shows how much the permanence of chest tube influences pulmonary function. This fact was also reported in other surveys of general thoracic surgery ${ }^{36-38}$. Lima et al. ${ }^{39}$ found $49.7 \%$ reduction in pain after tube removal.

Some factors may influence lung function by itself, such as age, chronic obstructive pulmonary disease, and duration of surgery. We consider all these factors as exclusion criteria, which made it difficult to find a higher sample in our study, as in the outpatient clinic of our hospital, the coronary patient is often a smoker, obese, and elderly. This fact, however, may be considered a bias.

\section{CONCLUSION}

Chest tube placed in the subxiphoid region provided better recovery of pulmonary function and less sensitivity to pain. 


\section{REFERENCES}

1. Imura H, Caputo $\mathrm{M}$, Lim $\mathrm{K}$ et al. - Pulmonary injury after cardiopulmonary bypass: beneficial effects of low-frequency mechanical ventilation. J Thorac Cardiovasc Surg, 2009;137:1530-1537.

2. Pick A, Dearani J, Odell J - Effect of sternotomy direction on the incidence of inadvertent pleurotomy. J Cardiovasc Surg, 1998;39:673676.

3. Taggart DP, el-Fiky M, Carter R, Bowman A et al. - Respiratory dysfunction after uncomplicated cardiopulmonary bypass. Ann Thorac Surg, 1993;56:1123-1128.

4. Hagl C, Harringer W, Gohrbandt B et al. - Site of pleural drain insertion and early postoperative pulmonary function following coronary artery bypass grafting with internal mammary artery. Chest, 1999;115:757761.

5. Peng MJ, Vargas FS, Cukier A et al. - Postoperative Pleural Changes after Coronary Revascularization - Comparison between SaphenousVein and Internal Mammary Artery Grafting. Chest, 1992;101:327330 .

6. Shapira N, Zabatino SM, Ahmed S et al. - Determinants of pulmonary function in patients undergoing coronary bypass operations. Ann Thorac Surg, 1990;50:268-273.

7. Guizilini S, Gomes WJ, Faresin SM et al. - Influence of pleurotomy on pulmonary function after off-pump coronary artery bypass grafting. Ann Thorac Surg, 2007;84:817-822.

8. Kollef MH, Peller T, Knodel A et al. - Delayed pleuropulmonary complications following coronary artery revascularization with the internal mammary artery. Chest, 1988;94:68-71.

9. Vargas FS, Uezumi KK, Janete FB et al. - Acute pleuropulmonary complications detected by computed tomography following myocardia revascularization. Rev Hosp Clin Fac Med São Paulo, 2002;57:135142.

10. Guizilini S, Gomes WJ, Faresin SM et al. - Effects of the pleural drain site on the pulmonary function after coronary artery bypass grafting. Rev Bras Cir Cardiovasc, 2004;19:47-54.

11. Bjessmo S, Hylander S, Vedin J et al. - Comparison of three different chest drainages after coronary artery bypass surgery - A randomised trial in 150 patients. Eur J Cardiothorac Surg, 2007;31:372-375.

12. Frankel TL, Hill PC, Stamou SC et al. - Silastic drains vs conventional chest tubes after coronary artery bypass. Chest, 2003;124:108-113.

13. Kollef MH, Dothager DW - Reversible cardiogenic shock due to chest tube compression of the right ventricle. Chest, 1991;99:976-980.

14. Castro Pereira CA - Espirometria em diretrizes para testes de função pulmonar 2002. J Bras Pneumol, 2002;28(Supl 3):S2-S82.

15. Eveleth PB, Andres R, Chumlea WC et al. - Uses and interpretation of antrhropometry in the elderly for the assessment of physical status. Report to the Nutrition Unit of the World Health Organization: the Expert Subcommittee on the Use and Interpretation of Anthropometry in the Elderly. J Nutr Health Aging, 1998;2(1):5-17.

16. Oliveira MVC, Oliveira TR, Pereira CAC et al. - Tabagismo em pacientes internados em um hospital geral. J Bras Pneumol, 2008;34:936941.

17. Berrizbeitia LD, Tessler S, Jacobowitz IJ et al. - Effect of Sternotomy and Coronary-Bypass Surgery on Postoperative Pulmonary Mechanics - Comparison of Internal Mammary and Saphenous-Vein Bypass Grafts. Chest, 1989;96:873-876.

18. Singh NP, Vargas FS, Cukier A et al. - Arterial blood gases after coronary artery bypass surgery. Chest, 1992;102:1337-1341. 
19. Christenson JT, Aeberhard JM, Badel P et al. - Adult respiratory distress syndrome after cardiac surgery. Cardiovasc Surg, 1996;4:15-21.

20. Taniguchi L, Pinheiro A - Particularidades do atendimento ao paciente em pós-operatório de cirurgia cardíaca, em: Regenga M - Fisioterapia em Cardiologia: Da UTI à Reabilitação. São Paulo, Roca, 2000, pp 121-154.

21. Regan K, Kleinfeld M, Erik P - Fisioterapia para pacientes com cirurgia abdominal ou torácica. Em: Irving S, Tecklin J - Fisioterapia cardiopulmonar. São Paulo, Manole, 1994, pp. 318-339.

22. Jenkins SC, Soutar SA, Forsyth $A$ et al. - Lung function after coronary artery surgery using the internal mammary artery and the saphenous vein. Thorax, 1989;44:209-211.

23. O'Brien JW, Johnson SH, VanSteyn SJ et al. - Effects of internal mammary artery dissection on phrenic nerve perfusion and function. Ann Thorac Surg, 1991;52:182-188.

24. Brooks-Brunn JA - Postoperative atelectasis and pneumonia: risk factors. Am J Respir Crit Care Med, 1995;4:340-9; quiz 350-351.

25. Galantier J - Particularidades da circulação extracorpórea. Em: Auler Jr JOC \& Oliveira AS - Pós-operatório de cirurgia torácica e cardiovascular. Porto Alegre, Artmed, 2004, pp. 153-157.

26. Cohen AJ, Moore $P$, Jones $C$ et al. - Effect of internal mammary harvest on postoperative pain and pulmonary function. Ann Thorac Surg, 1993;56:1107-1109.

27. Burgess GE, Cooper JR, Marino RJ et al. - Pulmonary effect of pleurotomy during and after coronary artery bypass with internal mammary artery versus saphenous vein grafts. J Thorac Cardiovasc Surg, 1978;76:230-234.

28. Riebman JB, Olivenciayurvati AH, Laub GW - Improved Technique for Pleural Drain Insertion during Cardiovascular-Surgery. J Cardiovasc Surg, 1994;35:503-505.

29. Giacomazzi CM, Lagni VB, Monteiro MB - Postoperative pain as a contributor to pulmonary function impairment in patients submitted to heart surgery. Rev Bras Cir Cardiovasc, 2006;21:386-392.

30. Oikkonen M, Karjalainen $\mathrm{K}$, Kahara $\mathrm{V}$ et al. - Comparison of incentive spirometry and intermittent positive pressure breathing after coronary artery bypass graft. Chest, 1991;99:60-65.

31. Chon KS, vanSonnenberg E, D'Agostino HB, O'Laoide RM, Colt HG, Hart E - CT-guided catheter drainage of loculated thoracic air collections in mechanically ventilated patients with acute respiratory distress syndrome. AJR Am J Roentgenol, 1999;173:1345-1350.

32. Lancey RA, Gaca C, Vander Salm TJ - The use of smaller, more flexible chest drains following open heart surgery: an initial evaluation. Chest, 2001;119:19-24.

33. Nunez R, Munoz JA, Vazquez F et al. - Effects of several methods of thoracic drainage on respiratory function. Cir Pediatr, 1996;9:28-31.

34. Duggan M, Kavanagh BP - Pulmonary atelectasis: a pathogenic perioperative entity. Anesthesiology, 2005;102:838-854.

35. Wheatcroft M, Shrivastava V, Nyawo B et al. - Does pleurotomy during internal mammary artery harvest increase post-operative pulmonary complications? Interact Cardiovasc Thorac Surg, 2005;4:143-146.
36. Jakob H, Kamler M, Hagl S - Doubly angled pleural drain circumventing the transcostal route relieves pain after cardiac surgery. Thorac Cardiovasc Surg, 1997;45:263-264.

37. Gómez-Caro A, Roca MJ, Torres $\mathrm{J}$ et al. - Successful use of a single chest drain post-lobectomy instead of two classical drains: a randomized study. Eur J Cardiothorac Surg, 2006;29:562-566.

38. Mueller XM, Tinguely F, Tevaearai HT et al. - Impact of duration of chest tube drainage on pain after cardiac surgery. Eur $\mathrm{J}$ Cardiothorac Surg, 2000;18:570-574.

39. Lima VP, Bonfim D, Risso TT et al. - Influence of pleural drainage on postoperative pain, vital capacity and six-minute walk test after pulmonary resection. J Bras Pneumol, 2008;34:1003-1007. 